\title{
Apontamentos conceituais sobre a noção de transgressão ${ }^{1}$
}

\author{
Conceptual notes on the notion of transgression
}

\author{
Wilton Divino da Silva Júnior ${ }^{2}$ \\ Universidade Federal de Goiás - UFG \\ wuiltonufg@gmail.com
}

\begin{abstract}
RESUMO: Este texto, síntese de minha tese A transgressão nos estudos do discurso: caminhos para uma operacionalização conceitual (2018), fundamentase em uma abordagem foucaultiana dos discursos, inscrevendo-se em uma postura filosófica, muito mais do que em uma teoria ou método. Neste texto, ensaia-se uma escrita menos provável, porém não impossível para um gênero textual acadêmico com vistas não somente a dissertar sobre, mas demonstrar as estratégias de rupturas características das práticas transgressoras. Simultaneamente, buscou-se evidenciar os pontos em que algumas noções foucaultianas contribuem para iluminar formulações conceituais e operacionais da ideia de transgressão. Esta pesquisa assume um caráter epistemológico, pois objetiva pensar a construção de um sistema de formação conceitual. Portanto, a partir do apontamento de Foucault sobre a transgressão em um texto de 1963, identificamos, neste estudo, sete apontamentos conceituais para a ideia de transgressão, quais sejam: (1) "a transgressão é um gesto relativo ao limite"; (2) a transgressão é da ordem do acontecimento; (3) a transgressão é uma discussão em torno da verdade; (4) a transgressão é um investimento discursivo; (5) a transgressão é uma máquina discursiva que move a pertinência da tradição; (6) a transgressão é estratégia de resistência; (7) a transgressão é uma das linhas de força constitutivas de um dispositivo.
\end{abstract}

Palavras-chave: Transgressão; Abordagem foucaultiana; Formação conceitual.

\begin{abstract}
This text, synthesis of my thesis The transgression in discourse studies: ways for a conceptual operationalization (2018), is based on a Foucauldian approach to discourse, inscribing itself in a philosophical position, much more than in a theory or method. In this article, we write a less probable but not impossible writing for an academic textual genre aiming not only to dissert about, but to demonstrate the rupture strategies characteristic of the transgressive practices. Simultaneously, I tried to highlight the points in which the Foucauldian notions contribute to illuminate conceptual and operational formulations of the idea of transgression. This research assumes an epistemological posture, because it aims to think the construction of a system of conceptual formation. Therefore, starting with Foucault's point of view on transgression in a text of 1963, we identify seven conceptual points for the idea of transgression, namely: (1) "transgression is a gesture concerning the limit "; (2) transgression is of the order of the event; (3) transgression is a discussion about truth; (4) transgression is a discursive investment; (5) transgression is a discursive machine that moves the
\end{abstract}

\footnotetext{
${ }^{1}$ Texto produzido para o III Colóquio Cartografias do Contemporâneo, realizado na Universidade Federal de Uberlândia nos dias 5, 6 e 7 de dezembro de 2018. Mesa redonda: Subjetividade, violência e resistência.

${ }^{2}$ Professor Adjunto da Faculdade de Letras da Universidade Federal de Goiás.
} 
relevance of tradition; (6) transgression is a strategy of resistance; (7) transgression is one of constituents of an apparatus (dispositif).

Keywords: Transgression; Foucauldian approach; Conceptual formation. 
Hoje minha fala está coagida pelo ato de ler (que é também estratégia para que eu "bem-diga"). Procuro resistir ao fluxo das emoções. A institucionalidade acadêmica deste espaço insiste, como uma voz inaudita, para que eu me oriente de modo racional e informativo sob os equívocos de uma neutralidade de escrita que me obriga a um dizer que me afasta de mim, que me reconduz, que me vigia e controla. Leio, porque em alguma medida resisto aos afetos que me constituem neste momento, dado que, na academia, espaço geopolítico da racionalidade, fundamentamo-nos na razão, nos processos argumentativos que durante muito tempo deveriam ter iluminado as consciências para uma vida melhor e plena.

Mas não resistirei muito tempo, re(exist)irei, porque eu posso falar, enunciando de um lugar que me articula em posições marcadas pela heterogeneidade dos discursos, das polêmicas, dos conflitos, das repetições, das retomadas, e, certamente, das transgressões. Sim, eu discursivizo um mundo que me objetiva, que me desejar moldar, que me quer como seu, mas também (re)estetizo minha existência, (re)paro o outro e neste (re)encontro empático, eu (re)existo. Portanto, o que faço com vocês neste instante é partilhar vivências, narrando minhas histórias.

Minhas questões, inicialmente, pareciam procurar uma definição que melhor pontuasse o espectro de ações e acontecimentos transgressores; foi quando compreendi que tratando da transgressão, na verdade, eu queria, e precisava urgentemente, falar de limites. Eu queria determinar, delimitar as práticas transgressoras, e só me dei conta muito tempo depois de que eu estava numa busca autoritária não para observar a relação entre limites e transgressões, mas para fazer os limites funcionarem de modo mais eficaz para que eles pudessem dar conta, (e por "dar conta" entendam submeter, controlar) os discursos e práticas transgressoras. Eu estava agindo como um fascista! Meu incômodo era justamente com a instabilidade das transgressões, portanto dos discursos que escapam e resistem.

Carlos Felipe Moisés (1942-2017), poeta, tradutor, critico literário, professor e autor de diversas obras, num texto de 2008 intitulado "Dialética da transgressão" afirma que "[...] inovar e transgredir passaram a ser encarados não só com benevolência mas com indisfarçável simpatia, vindo a contar, in limine, com aprovação e aplausos gerais". O autor utiliza duas expressões para se referir a essa questão: hipertrofia e protocolar. Aplica, portanto, dois pontos importantes para compreender a transgressão, isto é, a transgressão como conceito cuja ampliação excedeu os próprios limites do conceito; além de ser uma ultrapassagem padronizada, um tanto burocratizada, praticamente institucional (o que produz um paradoxo a beirar o sarcasmo). 
Mas isso também me permitiu vislumbrar outro modo de análise. Como afirma o filósofo francês:

[...] nas relações de poder, há necessariamente possibilidade de resistência, pois se não houvesse possibilidade de resistência - de resistência violenta, de fuga, de subterfúgios, de estratégias que invertam a situação -, não haveria de forma alguma relações de poder (FOUCAULT, 2006c, p. 277).

Ora, ponto unânime, há resistências. A questão posta apontava para uma investigação acerca da natureza das resistências: de que maneira delimitá-las como transgressão? A dicotomia inovação x manutenção parecia dar cabo de alguns aspectos deste problema, mas escapavam-lhe características, mais rizomáticas, que estavam estampadas em uma série de práticas, porém invisibilizadas em algumas análises, e que me permitiram compreender a natureza da minha vontade taxionômica com relação às práticas de transgressão, bem como complexificar minha compreensão acerca do assunto pela noção de "dispositivo".

Academicamente, foi o texto "Prefácio à transgressão", escrito em 1963, por Michel Foucault, aquilo que me encaminhou para as discussões sobre transgressão e discurso. Neste prefácio à publicação das obras completas de George Bataille, Foucault trata da transgressão na produção literária do referido escritor francês. O que move inicialmente suas reflexões sobre o tema, empiricamente, refere-se à produção literária de Roussel, Blanchot, Bataille e Artaud; posteriormente, no fim da década de 1960 e início de 1970, quando elege outros objetos de pesquisa, observa-se um estudo que se aprofunda na noção de resistência e culmina nos estudos sobre a ética de si, portanto, no abandono de uma "teoria" da transgressão.

Diogo Sardinha, professor de filosofia da Universidade de Paris I, num texto publicado em 2010 na revista Trans/Form/Ação trata de duas ontologias críticas na obra de Foucault, a primeira do início dos anos 1960, voltada para a construção de uma teorização da transgressão e do excesso; e a segunda iniciada nos anos 1980 que, fundamentada na ética, volta-se para a teorização da ascese e da medida. Ontologias críticas cujos movimentos, apesar de divergentes - a primeira focada na noção de suplício do sujeito e a segunda na busca das relações de si a si -, guardam preocupações comuns a partir de três pontos temáticos tratados, a saber, a sexualidade, os limites e o ser.

Para Foucault (2006, p. 32), “a transgressão é um gesto relativo ao limite”, isto é, o espaço da transgressão, de sua passagem, é o da espessura da linha, do limite. Neste espaço, a transgressão ocorre, porém não se encontra submetida a ele, pois aponta ao limite a iminência de sua desaparição, o ilimitado; ao mesmo tempo em que constitui sua existência reforçando 
também a existência do limite que ela atravessa. Este é o jogo dos limites e das transgressões: há uma transposição do limite, porém que se fecha logo atrás através de uma memória que reativa aspectos do limite em face do atravessamento sofrido. Parece ser um jogo que funciona em espiral. As transgressões fissuram o limite em diversos pontos até que esse limite cicatrizado não é mais o anterior. Entretanto, a transgressão pode ser capturada pelo funcionamento do sistema, despontando como norma abrindo possibilidades para novas transgressões num outro ponto da espiral.

Transgressão e limite se relacionam não por oposição, como o preto está para o branco ou o proibido para o permitido, mas numa relação em que um não nega o outro, e sim coexistem de modo interdependente: há existência verdadeira para o limite fora do gesto transgressor que o atravessa? A transgressão não se esgota após transpor o limite (sua existência não se manteria somente naquele dado ponto)? Foucault reconhece a transgressão como uma experiência-limite, procurando distanciar-se da compreensão fenomenológica de uma experiência do cotidiano que deseja encontrar as significações a partir de um sujeito fundador, e aproxima-se da ideia de experiência em Nietzsche, Blanchot e Bataille. Há uma emergência circunstancial da figura do sujeito transgressor, dado o aspecto de movência e atravessamento da transgressão que "arranca" o sujeito da transcendência e o aniquila/remodela, por isso a necessidade de pensar nas relações estabelecidas de si para si, como faz o filósofo e historiador francês nos anos 1980. Portanto o que ele defende não é uma soberania inescapável dos sistemas coercitivos, mas o reconhecimento da construção de um sujeito existente num mundo partilhado, explicitado por Foucault nas pesquisas em torno do sujeito ético (FOUCAULT, 2010).

Se, como estou abordando, a transgressão não instaura "o original”, "o nunca antes visto", diferentemente, possibilita a produção do novo, que se constitui não pela originalidade de seu conteúdo, mas no "acontecimento de sua volta" (FOUCAULT, 2006a, p. 26), entendemos, deste modo, a transgressão como investimento discursivo. Aqui, parece-me, reside um dos perigos da ordem do discurso científico-acadêmico, qual seja, a conjecturação de um conceito. Entretanto, amparado por uma abordagem foucaultiana do discurso, eu me aparto desse certame inglório para pensar acerca do feixe de relações de um sistema de formação conceitual da transgressão. Sendo assim, interessa-me pensar no "nível préconceitual" que não reconhece o conceito como idealidade atemporal instituída ou descoberta por um gesto fundador, nem o conjunto progressivo das ideias que puderam gerá-la; procuro colocar essa questão no nível do discurso como espaço de emergência dos conceitos (FOUCAULT, 2007). 
A transgressão é da ordem do acontecimento e funciona no interior dos dispositivos (conforme a noção foucaultiana) por procedimentos que deslocam, incorporam, silenciam, remodelam ou marcam a ausência dos enunciados, possibilitando uma reordenação estratégica do dispositivo principalmente em torno de uma construção ética do sujeito. Ela não necessariamente inverte, instaura ou apaga uma dada ordem para produzir uma nova, ou promove o caos; antes, simula e interfere, portanto, produz, em um mesmo dispositivo, um novo investimento.

A idéia geral deste estudo não foi buscar a formulação de um conjunto de procedimentos que viabilizem o tratamento sistemático da transgressão como categoria ou conceito reaplicável em diferentes objetos de pesquisa dos estudos discursivos, mas narrar aspectos de um percurso de estudos em torno da ideia de transgressão e sua funcionalidade estratégica para a análise de discursos.

Meus embates em torno da construção de um saber e fazer acadêmicos perduram. De um lado, conceitos e categorias tomadas aprioristicamente, funcionando como procedimentos aplicáveis a quaisquer objetos, com vistas à verificabilidade da serventia teórica e metodológica. Do outro, um saber que se construía pela descrição dos discursos e das práticas - descrição que não se restringia ao âmbito formal e contextual -, sem as etapas bem delimitadas de um método, além de um objeto-conceito (a transgressão) inusitado e incontrolável.

O embate acadêmico se resumia no jogo entre a divinização e a satanização teórica, e eu entrei nesse jogo sem vencedores, mas não era disso que se tratava o fazer acadêmico. Para este estudo guardo algumas esperanças: (a) procurei pensar COM Foucault, porque mais que usar as noções legadas, produtos de suas análises, busquei a postura filosófica pautada no olhar ético sobre a diferença; (b) inscrevo-me em um campo brasileiro de estudos discursivos, pensado no interior de grupos de estudos de análise do discurso e da obra foucaultiana, das Universidades Federais e Estaduais brasileiras, por professores, graduandos e pós-graduandos brasileiros, no tratamento de questões brasileiras; (c) entendi que uma abordagem foucaultiana dos discursos é constitutivamente transgressora, porque está na contramão de uma continuidade histórica progressiva dos acontecimentos e dos processos de homogeneização dos discursos e das práticas.

As histórias deste estudo foram "inventadas", assim como são todas as histórias. Pura invenção: desejo de memória, portanto, medo da morte. Medo das infinitas mortes cotidianas que nos assombram. Desejo de prevalecer, permanecer, de eternizar-se na imaterialidade dos bens simbólicos. Eu me inventei no/pelo outro, e me reconheci constitutivamente múltiplo, 
quando me dei conta de que pensar a emergência dos enunciados e práticas transgressoras, era, irrevogavelmente, pensar-me no jogo dos limites e das transgressões. Isto é, a partir dos processos, que me possibilitaram modos de ser, de uma dada economia dos discursos de verdade sobre homossexualidade, da dessubjetivação do sujeito religioso, da resistência como prática instauradora de poder, da possibilidade de uma postura filosófica, não mais científica, diante dos "homens infames"; eu me reconheci no interstício do jogo, entre os limites e as transgressões.

A partir dessas histórias e desses embates algo foi feito, produto de escolhas, de iluminações e de sombreamentos, de coerções e de transgressões. Para mim, o uso inflacionado da palavra "transgressão" ocultava certa falta de clareza acerca de seu significado, porém, supostamente destituído da tarefa de formular um conceito para transgressão, já pensando na descrição de seu funcionamento discursivo, acabei por enredarme na exploração sobre a formação de um conceito, e sete apontamentos conceituais vieram à tona.

A transgressão é (a) "um gesto relativo ao limite"; (b) da ordem do acontecimento; (c) uma discussão em torno da verdade; (d) um investimento discursivo; (e) estratégia de resistência; (f) máquina discursiva que move a pertinência da tradição; (g) linha de força constitutiva dos dispositivos, que, como parte de um conjunto, pode rearranjar estrategicamente os elementos heterogêneos de um dispositivo.

Porque há uma necessária relação entre ruptura e regularidade histórica, na medida em que aquela produz novas formas desta, consideramos a transgressão como uma noção da ordem do acontecimento dada a possibilidade de análise e descrição das regularidades discursivas em torno das fissuras históricas. Pensar a transgressão é considerar um dos vários aspectos para o diagnóstico do presente.

Porque há vontades, regimes e jogos de verdade, que desessencializaram a perspectiva unificadora de verdade, a transgressão é, também, a fissura possível no interior das mais diversas práticas institucionais, mantendo-as em perpétua reordenação.

Recordo-me de um trecho do diálogo entre Alice e HumptyDumpty, personagens de Lewis Carroll, em Alice através do espelho e o que ela encontrou lá:

- Quando eu uso uma palavra - Humpty Dumpty disse em tom de troça - ela quer dizer apenas o que eu quero que ela queira dizer... nem mais, nem menos.

- A questão é - disse Alice - se você consegue fazer as palavras dizerem tantas coisas diferentes.

- A questão é - disse Humpty Dumpty - quais você domina... só isso. [...] 
- É muita coisa para você querer dizer com uma palavra só - Alice disse em tom ponderado.

- Quando eu faço uma palavra ter que dizer tanto - disse Humpty Dumpty sempre pago um tanto a mais. (CARROLL, 2015, p. 112-115, grifo do autor)

Fazer a palavra transgressão "dizer tanto", tornou-me esse ovo falante, senhor de si e das palavras, que pagará "um tanto a mais" por se apropriar dos desdobramentos da linguagem, dos discursos e das práticas. Havia uma Alice, leitora-fantasma deste estudo, que pontuava minha arrogância no domínio das palavras, e que me fez reconhecer que, diferentemente de Humpty, eu estava no interior dos jogos de linguagem, na ilusão de um controle sobre a língua. Sim, eu disse muita coisa em uma palavra só, mas em uma palavra que nunca esteve isolada, mas sempre na trama, sempre no jogo.

Todos aqueles apontamentos conceituais funcionam em conjunto, um não exclui o outro, pois, na verdade, são aspectos que se complementam para a construção da noção de transgressão e para tratar de seu funcionamento nos discursos e nas práticas. Os questionamentos pareciam nunca cessar. A seguinte questão moveu-me: quais as implicações em afirmar que a transgressão é uma ação em relação necessária com limites estabelecidos?

Muito tempo depois, mesmo reconhecendo que as implicações são muitas, identifiquei uma delas que julgo fundamental: a possibilidade de um modo de ser estético para a construção de uma existência bela (como Foucault retoma em 1984 estudando a vida cínica). $\mathrm{Na}$ formulação de uma subjetividade transgressora, dada pela discussão sobre a economia dos enunciados verdadeiros, investe-se estética e semanticamente nos discursos e nas práticas, reconfigurando, a partir das estratégias de resistência, as formas de poder/governo de si mesmo e dos outros. Esse é o jogo das transgressões no limiar das prescrições, das normatizações e das normalizações, em um ciclo espiralado constante, mas imprevisível, que inventa um sujeito transgressor atuante na vida mesma, partindo da alteração dos valores para a formulação de uma vida "que é vida outra neste mundo" (SOUSA, 2017, p. 117).

Vivemos tempos de re(exist)ência. Minha vida, nossas vidas estão em perigo. Foram postas em perigo discursivamente, simbolicamente, concretamente. Mais uma vez, 'transgredir' e 'subverter' ressurgem como estratégias de resistência necessárias para nos manter vivos. A "língua de branco", como um dia afirmou o xamã yanomani Kopenawa na obra A queda do céu de 2010, não pode continuar como língua de fantasma, esfumaçada e obscura marcada nas peles de papel. Nossas palavras marcam nossas peles, inscrevem-se como transgressão em nossos corpos e convulsionam os discursos. Neste momento em que os limites se fortalecem como novos muros para destituir e matar existências, também, na mesma 
medida, ganham força as transgressões e subversões; fortalecem-se as resistências: esse existir outro com o outro neste mundo. Termino aqui com Foucault, num trecho de "É inútil revoltarse?" de 1979:

E porque o homem que se rebela é em definitivo sem explicação, é preciso um dilaceramento que interrompa o fio da história e suas longas cadeias de razões, para que um homem possa, 'realmente', preferir o risco da morte à certeza de ter de obedecer (FOUCAULT, 2006b, p. 77).

\section{Referências}

CARROLL, Lewis. Alice através do espelho e o que ela encontrou lá. Tradução de Alexandre Barbosa de Souza. São Paulo: Cosac Naify, 2015.

FOUCAULT, Michel. Prefácio à Transgressão [1963]. In: FOUCAULT, Michel. Estética: literatura e pintura, música e cinema (Ditos e escritos. v. III). Organização e seleção de textos: Manoel Barros da Motta. Tradução de Inês Autran Dourado Barbosa. 2. ed. Rio de Janeiro: Forense Universitária, 2006, p. 28-46.

FOUCAULT, Michel. A ordem do discurso [1970].13. ed. São Paulo: Edições Loyola, 2006a.

FOUCAULT, Michel. É inútil revoltar-se? [1979]. In: FOUCAULT, Michel. Ética, sexualidade e política (Ditos e escritos. v. V). Organização e seleção de textos: Manoel Barros da Motta. Tradução de Elisa Monteiro e Inês Autran Dourado Barbosa. 2. ed. Rio de Janeiro: Forense Universitária, 2006b, p. 77-81.

FOUCAULT, Michel. A ética do cuidado de si como prática de liberdade [1984]. In: FOUCAULT, Michel. Ética, sexualidade e política (Ditos e escritos. v. V). Organização e seleção de textos: Manoel Barros da Motta. Tradução de Elisa Monteiro e Inês Autran Dourado Barbosa. 2. ed. Rio de Janeiro: Forense Universitária, 2006c, p. 264-287.

FOUCAULT, Michel. A arqueologia do saber [1969]. Tradução de Luiz Felipe Baeta Neves. 7. ed. Rio de Janeiro: Forense Universitária, 2007.

FOUCAULT, Michel. Conversa com Michel Foucault [1980]. In: FOUCAULT, Michel. Repensar a política (Ditos e escritos, v. VI). Tradução de Ana Lúcia Paranhos Pessoa. Organização e seleção de textos Manoel Barros da Motta. Rio de Janeiro: Forense Universitária, 2010, p. 289-347.

MOISÉS, C. F. Dialética da transgressão. Revista Dicta\&Contradicta, São Paulo, n. 2, dez. 2008. Disponível em: <http://www.dicta.com.br/edicoes/edicao-2/dialetica-da-transgressao/>. Acesso em: 30 dez. 2012.

SARDINHA, Diogo. As duas ontologias críticas de Foucault: da transgressão à ética. Revista Trans/Form/Ação, Marília, v. 33, n. 2, p. 177-192, 2010. DOI: https://doi.org/10.1590/S0101-31732010000200011 
SILVA JÚNIOR, Wilton Divino da. A transgressão nos estudos do discurso: caminhos para uma operacionalização conceitual [manuscrito]. Goiânia: 2018. 104f. Tese (doutorado em Letras e Linguística). Faculdade de Letras: Universidade Federal de Goiás, 2018.

SOUSA, Kátia Menezes de. A outra vida ou uma vida outra? O violento percurso para o paraíso dissimulado e a estética da existência. In: FERNANDES, Cleudemar Alves (org.). A violência na contemporaneidade: do simbólico ao letal. São Paulo: Intermeios, 2017, p. 113-133.

Recebido em: 17 de outubro de 2019

Aceito em: 18 de novembro de 2019 